\title{
Using ruminally protected and nonprotected active dried yeast as alternatives to antibiotics in finishing beef steers: growth performance, carcass traits, blood metabolites, and fecal Escherichia coli ${ }^{1}$
}

\author{
Tao Ran,,$" \dagger$ Yizhao Shen, ${ }^{*}$, Atef M. Saleem,,$" \|$ Ousama AlZahal, ${ }^{\$}$ Karen A. Beauchemin,* and \\ Wenzhu Yang*,2
}

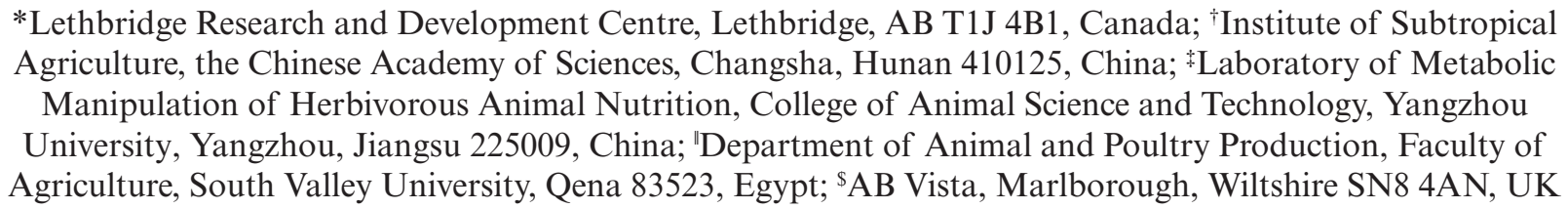

\begin{abstract}
The objective of this study was to evaluate the effects of supplementing the diet of finishing beef steers with active dried yeast (ADY) in ruminally protected and nonprotected forms on growth performance, carcass traits, and immune response. Seventyfive individually-fed Angus steers (initial body weight (BW) $\pm \mathrm{SD}, 448 \pm 8.4 \mathrm{~kg}$ ) were assigned to a randomized complete design with 5 treatments: 1) control (no monensin, tylosin, or ADY), 2) antibiotics (ANT, $330 \mathrm{mg}$ monensin $+110 \mathrm{mg}$ tylosin $\cdot$ steer $^{-1} \mathrm{~d}^{-1}$ ), 3) ADY $\left(1.5 \mathrm{~g} \cdot\right.$ steer $\left.^{-1} \mathrm{~d}^{-1}\right)$, 4) encapsulated ADY (EDY; $3 \mathrm{~g} \cdot$ steer $^{-1} \mathrm{~d}^{-1}$ ), and 5) a mixture of ADY and EDY (MDY; $1.5 \mathrm{~g} \mathrm{ADY}+3 \mathrm{~g} \mathrm{EDY} \cdot \mathrm{steer}^{-1} \mathrm{~d}^{-1}$ ). Active dried yeast with $1.7 \times 10^{10} \mathrm{cfu} / \mathrm{g}$ was encapsulated in equal amounts of ADY and capsule materials (stearic acid and palm oil). Steers were fed a total mixed ration containing 10\% barley silage and $90 \%$ barley-based concentrate mix (dry matter [DM] basis). The ANT, ADY, and EDY were top-dressed daily to the diet at feeding. Intake of DM, final BW, averaged daily gain (ADG), and gain-to-feed ratio (G:F) were unaffected by ADY or EDY. Carcass traits including hot carcass weight $(\mathbf{H C W})$, dressing percentage, marbling score and quality grade did not differ among treatments, although fewer severely abscessed livers were observed $(P<0.05)$ with ADY and MDY compared
\end{abstract}

with the other treatments. Plasma urea $\mathrm{N}$ tended $(P<0.10)$ to be greater in steers fed ANT, ADY, or EDY on day 56 and 112, while glucose remained stable in all treatments except greater $(P<0.02)$ plasma glucose occurred in steers fed MDY on day 112. Serum nonestrified fatty acid (NEFA) was unaffected by ADY or EDY, but it was greater $(P<0.03)$ in steers fed ANT compared with control. Plasma haptoglobin (Hp) and serum amyloid A (SAA) were affected by yeast supplementation on day 112, with greater $(P<0.01) \mathrm{Hp}$ in steers fed ADY, EDY, or MDY and lesser $(P<0.01)$ SAA in steers fed EDY and MDY than control. Lipopolysaccharide binding protein concentrations were greater $(P<0.01)$ in steers fed EDY and MDY on day 56. Supplementing with ADY (protected or nonprotected) or ANT had no effect on fecal IgA contents on day 56 and 112. Steers fed yeast (EDY or MDY) tended $(P<0.10)$ to have fewer fecal Escherichia coli counts than the control and ANT on day 56 and 112. These results indicate that feeding ADY to feedlot cattle may exhibit antipathogenic activity that conferred health and food safety beneficial effects including reduced liver abscess and potentially pathogen excretion, thus yeast may be an alternative to in-feed antibiotics in natural beef cattle production systems.

Key words: active dried yeast, antibiotics, beef steers, growth performance, immune response

\footnotetext{
${ }^{1}$ This research was funded by the Alberta Agriculture and Forestry (\#2015E006R) and AB Vista (Marlborough, UK). We thank King Techina Feed Co, Ltd, in Hangzhou, China for preparing live yeast encapsulation. We acknowledge the Lethbridge Research and Development Centre barn staff for their care and management of the animals, and Alastair
}

Furtado, Karen Andrews, Rena Roth, and Darrell Vedres for their assistance with the laboratory analyses.

Contribution\#: 38718037

${ }^{2}$ Corresponding author: wenzhu.yang@agr.gc.ca

Received April 20, 2018.

Accepted July 3, 2018. 
(C) Crown copyright 2018. This article contains public sector information licensed under the Open Government Licence v3.0 (http://www.nationalarchives.gov.uk/doclopen-government-licencelversion/3/).

J. Anim. Sci. 2018.96:4385-4397 doi: $10.1093 /$ jas/sky272

\section{INTRODUCTION}

Antibiotics are widely used in North American feedlot operations to promote feed efficiency, growth performance, and animal health (Ashima et al., 2016). However, the use of antibiotics as growth promotants is under increased scrutiny because of potential antibiotic residue accumulation in animal products and increasing risk of antimicrobial resistant pathogens (WHO, 2006). Probiotics have been studied as alternatives to antibiotics, and some have been demonstrated to improve feed digestibility, enhance feed efficiency, reduce risk of intestinal infections, and restore gut microflora in some studies (Liong, 2007; Abd El-Tawab et al., 2016).

Active dried yeast (ADY) has been the main probiotic studied in ruminants and it has been shown to have a range of beneficial effects on rumen fermentation and nutrient digestibility (Denev et al., 2007; McAllister et al., 2011). Additionally, ADY demonstrates activity against zoonotic pathogens and thus may improve gut health, intestinal microbial balance (Broadway et al., 2015), and postruminal digestion in ruminants if it is metabolically active in the lower digestive tract (Jiao et al., 2017). However, few studies have been conducted to examine the postruminal effects and on immune responses to ADY in ruminants. Recently, Jiao et al. (2017) reported that ruminally protected ADY fed to heifers was released in the small intestine and increased the intestinal digestibility of nutrients. We hypothesize that feeding ruminally protected ADY would improve feed efficiency and lower gut immune response in finishing beef steers. Thus, the objective of this study was to determine the effects of supplementing diets with ruminally protected and nonprotected ADY on growth performance, carcass traits, animal health, and immune response in finishing beef steers. In addition, changes in blood metabolite concentrations and immune response with increasing days on-feed were also examined.

\section{MATERIALS AND METHODS}

The study was conducted in the Individual Feeding Facility at Agriculture and Agri-Food Canada's Research Centre in Lethbridge, Alberta. The study received approval of the institutional Animal Care Committee and was conducted in accordance with the guidelines of the Canadian Council on Animal Care (2009).

\section{Encapsulation of Yeast}

Active dried yeast (Saccharomyces cerevisiae, Biomate) was provided by $\mathrm{AB}$ Vista (Marlborough, Wiltshire, UK). The number of yeast colonies detected on potato dextrose agar medium was $1.7 \times 10^{10} \mathrm{cfu} / \mathrm{g}$ (Petran et al., 2001). Ruminally protected ADY was prepared as reported by Wang et al. (2011) using stearic acid and palm oil-based capsule material (King Techina Feed Co., Ltd, Hangzhou, China). Encapsulated ADY (EDY) consisted of equal amounts of ADY and capsule material. The stability of EDY in the rumen, abomasum and its release in the intestine were determined under simulated gastrointestinal conditions as described by Jiao et al. (2017). The nonencapsulated ADY lost activity after incubation in simulated rumen and abomasum fluids, while EDY was stable after incubation. The yeast was released from the capsule material after incubated in simulated intestinal fluid containing lecithin, bile salts, bile acid, and trypsin with over $90 \%$ survival rate (Shen et al., 2017).

\section{Animals, Design, and Treatments}

Seventy-five Angus steers were housed in individual feedlot pens $(4.9 \times 1.8 \mathrm{~m})$ bedded with sawdust in a sheltered barn. The steers were given 4 wk to adapt to the new environment and the high-grain finishing diet (Table 1) before starting the experiment. During the adaptation period, the steers were ear tagged and vaccinated following standard operating procedures of the beef facility. The experiment was a randomized complete design. The steers were initially weighed $(448 \pm 8.4 \mathrm{~kg})$ on 2 consecutive days, blocked by body weight (BW) and randomly allocated into 1 of 5 treatments. The treatments were: 1) control (no monensin, tylosin, or ADY), 2) antibiotics (ANT; $330 \mathrm{mg}$ monensin $+110 \mathrm{mg}$ tylosin $\cdot$ steer $\left.^{-1} \mathrm{~d}^{-1}\right), 3$ ) $\operatorname{ADY}\left(1.5 \mathrm{~g} \cdot\right.$ steer $\left.^{-1} \mathrm{~d}^{-1}\right)$, 4) EDY $\left(3 \mathrm{~g} \cdot\right.$ steer $\left.^{-1} \mathrm{~d}^{-1}\right)$, and 5) a mixture of ADY and EDY (MDY; $1.5 \mathrm{~g}$ ADY $\left.+3 \mathrm{~g} \mathrm{EDY} \cdot \mathrm{steer}^{-1} \mathrm{~d}^{-1}\right)$. The daily amount of antibiotics or yeast was mixed with $50 \mathrm{~g}$ of dry-rolled barley and delivered to each animal once daily by top-dressing onto the feed at feeding time. The control animals received a top-dress of $50 \mathrm{~g}$ of dryrolled barley without antibiotics or yeast. 
Table 1. Ingredients and chemical composition of the experimental diet (DM basis)

\begin{tabular}{lc}
\hline \hline Item & \\
\hline Ingredient, \% of DM & \\
Barley silage ${ }^{1}$ & 10 \\
Barley grain ${ }^{2}$, dry-rolled & 87 \\
Barley, ground & 0.92 \\
Canola meal & 0.83 \\
Calcium carbonate & 1.04 \\
Molasses & 0.04 \\
Salt & 0.09 \\
Feedlot premix ${ }^{3}$ & 0.02 \\
Urea & 0.06 \\
Vitamin E $(500,000$ IU/kg) & 0.002 \\
Canola oil & 0.02 \\
Chemical composition, $\%$ of DM & \\
DM, $\%$ & 74.9 \\
OM & 90.6 \\
CP & 12.5 \\
NDF & 17.7 \\
ADF & 5.3 \\
Starch & 52.3 \\
NEm ${ }^{4}$, Mcal/kg & 2.67 \\
NEg ${ }^{4}$, Mcal/kg & 1.90 \\
\hline
\end{tabular}

$\mathrm{ADF}$, acid detergent fiber; $\mathrm{CP}$, crude protein; NDF, neutral detergent fiber

${ }^{1}$ Composition (DM basis): $31.8 \%$ DM, 48.2\% NDF, 25.9\% ADF, $16.4 \%$ starch, and $12.1 \% \mathrm{CP}$ based on 4 samples composited by period.

${ }^{2}$ Composition (DM basis): $90.2 \% \mathrm{DM}, 97.0 \% \mathrm{OM}, 14.6 \% \mathrm{NDF}$, $3.7 \% \mathrm{ADF}, 55.9 \%$ starch and $14.5 \% \mathrm{CP}$ based on 4 samples composited by period.

${ }^{3}$ Supplied per kilogram of dietary DM: $15 \mathrm{mg} \mathrm{Cu}, 65 \mathrm{mg} \mathrm{Zn}, 28 \mathrm{mg}$ Mn, $0.7 \mathrm{mg} \mathrm{I}, 0.2 \mathrm{mg} \mathrm{Co}, 0.3 \mathrm{mg} \mathrm{Se}, 6,000 \mathrm{IU}$ vitamin A, 600 IU vita$\min \mathrm{D}$, and $47 \mathrm{IU}$ vitamin $\mathrm{E}$.

${ }^{4} \mathrm{NEm}$ and NEg were estimated from NRC (2000).

\section{Diet and Feeding}

Steers were fed a total mixed ration (TMR) containing $10 \%$ barley silage, $87 \%$ dry-rolled barley grain and $3 \%$ vitamin and minerals supplement (dry matter $[\mathbf{D M}]$ basis) to meet the nutrient requirements of finishing beef cattle (NASEM, 2016). Diet composition and nutrient ingredients are given in Table 1. The diets were prepared daily using a feed mixer (Data Ranger, American Calan Inc., Northwood, $\mathrm{NH})$ and the steers were fed ad libitum once daily at 0900 a.m. such that refusals in each feed bunk did not exceed approximately $5 \%$ of the daily amount fed. The steers had free access to water.

\section{Feed Sampling and Measurements}

Feed offered was recorded daily for each steer, and refusals were weighed weekly. Samples of dietary ingredients, diets, and refusals were collected weekly and subsampled for determination of DM content. The daily feed intake was calculated for each steer as the daily DM offered minus the weekly DM refused divided by 7 . Weekly samples (ingredients, TMR, and refusals) were pooled over 4-wk periods, mixed, subsampled, and dried in an oven at $55^{\circ} \mathrm{C}$ for $48 \mathrm{~h}$. The dried samples were then ground through a $1-\mathrm{mm}$ screen and stored for chemical analysis. Steers were weighed at the beginning and the end of the experiment and at 4-wk intervals during the experiment. The averaged daily gain (ADG) was determined for each 4-wk period and for the overall experiment by subtracting initial BW from BW at the end of the period or experiment and dividing by the number of days on-feed. Feed efficiency was determined as the ratio of ADG to dry matter intake (DMI). All feed and ingredient chemical analyses including DM, ash, organic matter (OM), neutral detergent fiber (NDF), acid detergent fiber (ADF), starch, and crude protein (CP) were carried out as described by Yang et al. (2010) with each sample performed in duplicate. If the coefficient of variation $(\mathbf{C V})$ for the replicate analysis was $>5 \%$, the analysis was repeated.

\section{Blood Sampling and Analysis}

Ten of the 15 steers from each treatment were randomly selected and blood samples were collected before feeding on day 0,56 , and 112 via jugular venipuncture. Two $10-\mathrm{mL}$ vacuum tubes containing $\mathrm{Na}$ heparin, and one $10-\mathrm{mL}$ vacuum tube without additive were obtained per animal at each sampling time (Vacutainer, Becton Dickinson, Franklin Lakes, NJ). Plasma samples were centrifuged at $3,000 \times g$ for $20 \mathrm{~min}$ at $4{ }^{\circ} \mathrm{C}$, and serum samples were centrifuged at 2,000 $\times g$ for $15 \mathrm{~min}$ at $4{ }^{\circ} \mathrm{C}$. Plasma and serum were frozen at $-20^{\circ} \mathrm{C}$ until analyzed. Blood glucose, blood urea N (BUN), and nonestrified fatty acid (NEFA) were determined as described by Yang et al. (2010). In brief, a subsample $(1 \mathrm{~mL})$ of the plasma was centrifuged at $16,000 \times$ $g$ for $2 \mathrm{~min}$ at $4{ }^{\circ} \mathrm{C}$ to remove fibrinogen, and the supernatant was analyzed for glucose and urea $\mathrm{N}$ using a dry chemistry analyzer (VetTest analyzer, model 8008, IDEXX Lab, Westbrook, ME), while concentrations of serum NEFA were determined using a commercially available enzymatic colorimetric procedure (NEFA-HR 2, Wako Chemicals Inc., Richmond, VA). Concentrations of serum amyloid A (SAA), plasma haptoglobin (Hp), and lipopolysaccharide binding protein (LBP) were determined using bovine ELISA kits (Cloud-Clone Corp., Katy, TX; Product No.: SEA885Bo, SEA817Bo 
and SEB406Bo) according to the manufacturer's instructions. The minimum detectable dose of SAA, $\mathrm{Hp}$, and LBP is typically less than $0.067 \mathrm{ng} / \mathrm{mL}$, $5.9 \mathrm{ng} / \mathrm{mL}$, and $0.287 \mathrm{ng} / \mathrm{mL}$, respectively.

\section{Fecal Sampling and Analysis}

At the same time of day that blood samples were collected, fresh feces (approximately $400 \mathrm{~g}$ wet) were collected via rectum from the same 10 steers per treatment used for blood sampling. The $\mathrm{pH}$ of the samples was measured immediately after sampling (Benchtop Meter, VWR International, Radnor, PA), and then the samples were subdivided into 2 portions and retained for determination of generic Escherichia coli counts and fecal IgA concentration. For total generic E. coli enumeration, $1 \mathrm{~g}$ of feces was weighed into a Hungate culture tube containing $9 \mathrm{~mL}$ of $0.1 \%$ peptone dilution water and vortexed vigorously. Serial dilutions to $10^{-6}$ were prepared in peptone water. One milliliter of $10^{-4}, 10^{-5}$ and $10^{-6}$ dilution was dispensed onto an E. coli Petrifilm plate (3M Canada, ON, Canada) and incubated at $35^{\circ} \mathrm{C}$ for $24 \mathrm{~h}$. After incubation, plates were counted and all blue colonies associated with gas bubbles were reported as $E$. coli $\left(10^{7}\right.$ cells $/ g$ feces). For IgA determination, $1 \mathrm{~g}$ of feces was weighed and placed immediately in ultra-purified water at a concentration of $10 \%(\mathrm{wt} / \mathrm{vol})$ by adding $9 \mathrm{~mL}$ of water in a $15 \mathrm{~mL}$ centrifuge tube. The tubes were vortexed and incubated overnight before centrifuging at $2,000 \times g$ for $15 \mathrm{~min}$ at $4{ }^{\circ} \mathrm{C}$. The supernatants were collected and analyzed for total IgA (Bovine IgA ELISA Quantitation Set, Bethyl Laboratories, Montgomery, TX).

\section{Carcass Traits}

At the end of the experiment, the steers were shipped to a commercial abattoir for slaughter. Hot carcass weights (with kidneys removed), dressing percentage, 12th-rib back fat thickness (BFT), longissimus muscle (LM) area, marbling score, quality grade, saleable meat yield, and abscessed livers were recorded for each carcass. Dressing percentage was calculated as hot carcass weight $(\mathbf{H C W})$ divided by final $\mathrm{BW} \times 100$. Marbling score was estimated according to pictorial standards from 1 (devoid) to 10 (abundant marbling; USDA, 1989). Quality grade was carried out as Canada AAA standards: Canada grade $\mathrm{A}$ is approximately equivalent to USDA Standard; AA is approximately equivalent to USDA Select; and AAA is approximately equivalent to USDA Choice. Saleable meat yield was estimated with consideration for the length, width, and fat cover of the rib eye muscle between the 11 th and 12 th rib, as estimated lean yield $=57.96-0.027$ HCW + 0.202 LM area -0.703 BFT. Liver abscess scores were determined based on the ranking scale used by the Canadian Beef Grading Agency. Severe liver abscesses were defined as liver with at least four small abscesses or at least one abscess with diameter larger than $2.5 \mathrm{~cm}$.

\section{Statistical Analysis}

The data for BW, DMI, ADG, and gain-to-feed ratio (G:F) were analyzed using the Mixed procedure of SAS (version 16.0.0, SAS Inst. Inc., Cary, NC) as a completely randomized design to account for time (days on feed) effects. The model included treatment, period (weigh day), and their interaction as fixed effects and steers within treatment as random effect. For repeated measures, various covariance structures were tested and AR(1) was selected based on the lowest value for Akaike's information criteria. Data for carcass characteristics, blood metabolites, acute phase proteins, fecal $\mathrm{pH}, \operatorname{IgA}$, and $E$. coli counts were analyzed using the Mixed procedure of SAS with treatment as fixed effects and steers within treatment as random effects. To test the effects of increasing days on-feed on blood and fecal variables, orthogonal contrasts were conducted to determine linear and quadratic responses. Meat quality grade and liver abscess data were analyzed using the GLIMMIX procedure (SAS Inst. Inc., Cary, NC). Least square means were compared using the Tukey correction for multiple comparisons, and treatment effects were declared significant at $P \leq 0.05$ and trends at $0.05<P \leq 0.10$.

\section{RESULTS}

\section{Growth Performance and Carcass Traits}

Treatment $\times$ period effects occurred $(P<0.05)$ for most variables measured, thus, the data are presented by treatment within period in the tables. Final BW was not affected by treatments (Table 2). During the first $28 \mathrm{~d}$, there were no differences in DMI of steers fed yeast (ADY, EDY, or MDY) compared with control, but ANT had lesser $(P<0.01)$ DMI than the other treatment. The DMI did not differ among treatments for the remaining periods, but overall the steers fed yeast (ADY, EDY, or MDY) had greater $(P<0.05)$ overall DMI than the steers fed ANT, while the overall DMI did not 
Table 2. Growth performance of finishing steers fed a diet supplemented with antibiotics (ANT), active dried yeast (ADY), encapsulated ADY (EDY), or mixture of ADY and EDY (MDY)

\begin{tabular}{|c|c|c|c|c|c|c|c|}
\hline \multirow[b]{2}{*}{ Item } & \multicolumn{5}{|c|}{ Treatments $^{1}$} & \multirow[b]{2}{*}{ SEM } & \multirow[b]{2}{*}{$P<$} \\
\hline & Control & ANT & ADY & EDY & MDY & & \\
\hline \multicolumn{8}{|l|}{$\overline{\mathrm{BW}, \mathrm{kg}}$} \\
\hline Initial & 448 & 448 & 448 & 448 & 448 & 8.4 & 1.00 \\
\hline Final & 627 & 623 & 628 & 625 & 631 & 10.9 & 0.99 \\
\hline \multicolumn{8}{|l|}{ DMI, kg/d } \\
\hline Day 1-28 & $9.97^{\mathrm{a}}$ & $8.82^{\mathrm{b}}$ & $10.11^{\mathrm{a}}$ & $9.81^{\mathrm{a}}$ & $10.35^{\mathrm{a}}$ & 0.32 & 0.01 \\
\hline Day 29-56 & 11.32 & 10.76 & 11.73 & 11.62 & 11.60 & 0.35 & 0.32 \\
\hline Day $57-84$ & 11.35 & 11.18 & 11.95 & 12.17 & 12.05 & 0.40 & 0.31 \\
\hline Day $85-112$ & 11.42 & 11.39 & 11.70 & 11.75 & 11.85 & 0.38 & 0.88 \\
\hline Overall & $11.0^{\mathrm{a}, \mathrm{b}}$ & $10.5^{\mathrm{b}}$ & $11.4^{\mathrm{a}}$ & $11.3^{\mathrm{a}}$ & $11.5^{\mathrm{a}}$ & 0.20 & 0.05 \\
\hline \multicolumn{8}{|l|}{$\mathrm{ADG}, \mathrm{kg} / \mathrm{d}$} \\
\hline Day 1 to 28 & $1.84^{\mathrm{b}}$ & $1.57^{\mathrm{c}}$ & $1.78^{\mathrm{b}}$ & $1.85^{\mathrm{b}}$ & $2.13^{\mathrm{a}}$ & 0.12 & 0.04 \\
\hline Day 29 to 56 & $1.74^{\mathrm{a}, \mathrm{b}}$ & $1.92^{\mathrm{a}}$ & $1.80^{\mathrm{a}}$ & $1.51^{\mathrm{b}}$ & $1.49^{\mathrm{b}}$ & 0.11 & 0.02 \\
\hline Day 57 to 84 & 1.40 & 1.31 & 1.50 & 1.65 & 1.64 & 0.11 & 0.13 \\
\hline Day 85 to 112 & 1.40 & 1.46 & 1.36 & 1.27 & 1.27 & 0.09 & 0.50 \\
\hline Overall & 1.59 & 1.57 & 1.61 & 1.57 & 1.63 & 0.06 & 0.94 \\
\hline \multicolumn{8}{|l|}{$\mathrm{G}: \mathrm{F}, \mathrm{g} / \mathrm{kg}$} \\
\hline Day 1 to 28 & 186.0 & 176.9 & 174.9 & 188.5 & 205.6 & 10.8 & 0.29 \\
\hline Day 29 to 56 & $155.4^{\mathrm{b}}$ & $178.6^{\mathrm{a}}$ & $154.2^{\mathrm{b}}$ & $130.6^{c}$ & $128.4^{\mathrm{c}}$ & 8.4 & 0.01 \\
\hline Day 57 to 84 & 122.2 & 114.1 & 125.6 & 135.7 & 136.4 & 8.1 & 0.26 \\
\hline Day 85 to 112 & 123.1 & 130.6 & 115.1 & 110.0 & 106.5 & 7.7 & 0.18 \\
\hline Overall & 146.7 & 150.1 & 142.5 & 141.2 & 144.2 & 4.7 & 0.58 \\
\hline
\end{tabular}

a,b,c Least square means within a row with different superscripts $\operatorname{differ}(P<0.05)$.

${ }^{1}$ Control $=$ no yeast and no antibiotics; ANT (330 mg monensin $+110 \mathrm{mg}$ tylosin $\left.\cdot \mathrm{steer}^{-1} \mathrm{~d}^{-1}\right)$; ADY $\left(1.5 \mathrm{~g} \mathrm{ADY} \cdot \mathrm{steer}^{-1} \mathrm{~d}^{-1}\right)$; EDY $\left(3 \mathrm{~g} \cdot \mathrm{steer}{ }^{-1} \mathrm{~d}^{-1}\right.$; EDY consisted of $1.5 \mathrm{~g}$ ADY and $1.5 \mathrm{~g}$ capsule material); and MDY (1.5 g ADY $+3.0 \mathrm{~g}$ EDY $\cdot$ steer $\left.^{-1} \mathrm{~d}^{-1}\right)$; Treatment $\times$ days on-feed were significant at $P<0.05$ for DMI, ADG, and G:F.

differ between the steers fed yeast and the control steers.

Average daily gain differed $(P<0.04)$ among treatments in the first 2 periods. During day 1 to 28 ADG was greatest $(P<0.04)$ for MDY, intermediate for ADY, EDY, and control, and least for ANT. However, from day 29 to 56, the ADG of steers supplemented with EDY and MDY was lesser $(P<0.02)$ than that of those supplemented with ADY, ANT, and control. No treatment effects on ADG were observed during day 57 to 84 , day 85 to 112, and overall. Feed efficiency measured as $\mathrm{G}: \mathrm{F}$ was not affected by treatments except during day 29 to 56, where G:F was greatest $(P<0.01)$ for ANT, least for EDY and MDY, and intermediate for ADY and control.

Carcass traits including $\mathrm{HCW}$, dressing percentage, BFT, LM area, marbling score, and saleable meat yield were not affected by treatments (Table 3). However, steers supplemented with ANT had $(P<0.01)$ lower quality grade when compared with the yeast supplementation and control groups. Proportion of abscessed livers did not differ, whereas, the proportion of severely abscessed livers was reduced $(P<0.05)$ by supplementing with ADY and MDY compared with the other treatments.

\section{Blood Metabolites and Immune Status}

Concentration of BUN did not differ among treatments on $\mathrm{d} 0$, but it tended $(P<0.10)$ to be greater on day 56 by supplementing ANT, ADY, or EDY, and on day 112 by supplementing ANT, ADY, EDY, or MDY compared with control (Table 4). Plasma glucose concentration was not different among treatments on day 0 and 56, but on day 112 it was greater $(P<0.02)$ for steers supplemented with MDY compared with control, ANT, or ADY, with EDY being intermediate and not different from the other treatments. Serum NEFA concentration on day 0 was similar for all treatments, but by day 56 it tended $(P<0.10)$ to differ with greater concentrations for ANT than for the other treatments. By day 112 , concentrations were greater $(P<0.03)$ for ANT compared with control and yeast treatments, which were similar.

There were interactions for plasma $\mathrm{Hp}$, SAA, and LBP concentration between treatment and days on feed (Table 5). There were no differences 
Table 3. Carcass characteristics of finishing steers fed a diet supplemented with antibiotics (ANT), active dried yeast (ADY), encapsulated ADY (EDY), or mixture of ADY and EDY (MDY)

\begin{tabular}{|c|c|c|c|c|c|c|c|}
\hline \multirow[b]{2}{*}{ Item } & \multicolumn{5}{|c|}{ Treatments $^{1}$} & \multirow[b]{2}{*}{ SEM } & \multirow[b]{2}{*}{$P<$} \\
\hline & Control & ANT & ADY & EDY & MDY & & \\
\hline$\overline{\mathrm{HCW}}, \mathrm{kg}$ & 369 & 366 & 373 & 368 & 369 & 6.62 & 0.96 \\
\hline Dressing, $\%$ & 58.9 & 58.7 & 59.4 & 59.1 & 58.9 & 0.33 & 0.66 \\
\hline BFT, mm & 19.2 & 20.1 & 18.9 & 18.2 & 19.0 & 1.23 & 0.87 \\
\hline $\mathrm{LM}$ area, $\mathrm{cm}^{2}$ & 86.1 & 82.7 & 88.9 & 87.3 & 86.7 & 1.88 & 0.20 \\
\hline Marbling score ${ }^{2}$ & 6.13 & 6.08 & 6.13 & 6.07 & 5.71 & 0.20 & 0.52 \\
\hline Saleable meat yield ${ }^{3}, \%$ & 51.9 & 50.7 & 52.7 & 52.9 & 52.1 & 1.09 & 0.63 \\
\hline \multicolumn{8}{|l|}{ Quality grade } \\
\hline $\mathrm{AAA}^{4}, \%$ & $100^{\mathrm{a}}$ & $86.7^{\mathrm{b}}$ & $100^{\mathrm{a}}$ & $100^{\mathrm{a}}$ & $100^{\mathrm{a}}$ & $\ldots$ & 0.01 \\
\hline \multicolumn{8}{|l|}{ Liver score, $\%$} \\
\hline Abscessed livers $5, \%$ & 46.7 & 60.0 & 60.0 & 46.7 & 53.3 & $\ldots$ & 0.75 \\
\hline Severely abscessed ${ }^{6}, \%$ & $26.7^{\mathrm{a}}$ & $26.7^{\mathrm{a}}$ & $6.7^{\mathrm{b}}$ & $20.0^{\mathrm{a}}$ & $6.7^{\mathrm{b}}$ & $\ldots$ & 0.05 \\
\hline
\end{tabular}

BFT, back fat thickness

a,b Least square means within a row with different superscripts differ $(P<0.05)$.

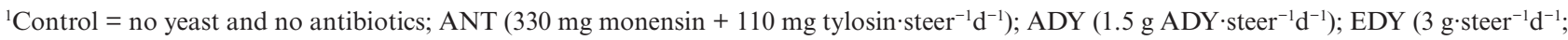
EDY consisted of $1.5 \mathrm{~g}$ ADY and $1.5 \mathrm{~g}$ capsule material); and MDY (1.5 g ADY + $3.0 \mathrm{~g}$ EDY $\left.\cdot \mathrm{steer}^{-1} \mathrm{~d}^{-1}\right)$.

${ }^{2}$ According to pictorial standards (from $1=$ devoid to $10=$ abundant marbling; USDA, 1989);

${ }^{3}$ Estimated lean yield $=57.96-0.027 \mathrm{HCW}+0.202 \mathrm{LM}$ area $-0.703 \mathrm{BFT}$; BFT $=12$ th-rib back fat thickness.

${ }^{4}$ Canada grade $\mathrm{AAA}=$ equivalent to USDA choice.

${ }^{5}$ The percentage of liver with at least 1 abscess.

${ }^{6}$ The percentage of liver with at least 4 small abscesses or at least 1 abscess with a diameter greater than $2.5 \mathrm{~cm}$.

in plasma $\mathrm{Hp}$ concentration among treatments on day 0 and 56, but it was greater $(P<0.01)$ for yeast treatments (ADY, EDY, and MDY) than control and ANT on day 112. Similarly, no differences in plasma SAA concentration were observed among treatments on day 0 and 56 , whereas the plasma SAA concentration was reduced $(P<0.01)$ on day 112 by supplementing ANT, EDY, or MDY, compared with control. No differences in plasma LBP concentration were observed among treatments on day 0 and 112, whereas on day 56 steers supplemented with EDY or MDY had greater $(P<0.01)$ plasma LBP concentration than steers fed control, ANT, or ADY. The LBP concentration increased $(P<0.01)$ considerably from day 0 to 56 without further change to day 112 in steers supplemented with EDY or MDY, whereas the LBP concentration did not change from day 0 to 56 but doubled from day 56 to 112 in control steers.

\section{Fecal IgA and E. coli Counts}

Fecal $\mathrm{pH}$ was not affected by treatments throughout the entire experimental period, whereas it linearly $(P<0.01)$ increased with increasing days on-feed except for the control and MDY steers (Table 6). Fecal IgA concentration in steers fed ANT was greater $(P<0.02)$ than the other treatments on day 0 . However, on day 56 and 112, there were no treatment effects on fecal IgA concentration. The fecal IgA concentration consistently declined $(P<0.01)$ with increasing days on feed with all treatments. The fecal $E$. coli counts tended $(P<0.07)$ to be different among treatments on day 0 and 56, with greater counts in the control and ANT steers on day 0 and greater counts in the ANT and EDY steers on day 56. There was no difference in fecal E. coli counts between control and ANT, whereas steers supplemented with ADY, EDY, or MDY tended $(P<0.07)$ to have lesser $E$. coli counts than control steers on day 112. Although the E. coli counts lowered from day 0 to 56 for all treatments, only counts for steers supplemented with EDY or MDY further declined $(P<0.01)$ from day 56 to 112 .

\section{DISCUSSION}

\section{Survival of EDY Under Simulated Gastrointestinal Conditions}

Yeast cell viability can be reduced during production, storage, and delivery as well as by the ruminal environment such as low $\mathrm{pH}$ when cattle are fed high-grain diets. Thus responses to ADY have been variable when it was used in animal studies (Sullivan and Bradford, 2011; Sartori et al., 2017). Fratianni et al. (2014) found dramatic loss of yeast cell viability after $4 \mathrm{wk}$ of storage at $4{ }^{\circ} \mathrm{C}$, 
Table 4. Blood metabolites of finishing steers fed a diet supplemented with antibiotics (ANT), active dried yeast (ADY), encapsulated ADY (EDY), or mixture of ADY and EDY (MDY)

\begin{tabular}{|c|c|c|c|c|c|c|c|}
\hline \multirow[b]{2}{*}{ Item } & \multicolumn{5}{|c|}{ Treatments $^{1}$} & \multirow[b]{2}{*}{ SEM } & \multirow[b]{2}{*}{$P<$} \\
\hline & Control & ANT & ADY & EDY & MDY & & \\
\hline$\overline{\text { Animal } \#^{2}}$ & 10 & 10 & 10 & 10 & 10 & & \\
\hline \multicolumn{8}{|c|}{$\mathrm{BUN}^{3}, \mathrm{mg} / \mathrm{dL}$} \\
\hline Day 0 & 6.71 & 6.44 & 7.09 & 7.07 & 6.87 & 0.45 & 0.85 \\
\hline Day 56 & 12.81 & 14.62 & 14.21 & 15.29 & 13.12 & 0.79 & 0.10 \\
\hline Day 112 & 10.29 & 12.25 & 10.81 & 12.21 & 12.07 & 0.69 & 0.10 \\
\hline Linear & 0.01 & 0.01 & 0.01 & 0.01 & 0.01 & & \\
\hline Quadratic & 0.01 & 0.01 & 0.01 & 0.01 & 0.01 & & \\
\hline \multicolumn{8}{|c|}{ Glucose, $\mathrm{mg} / \mathrm{dL}$} \\
\hline Day 0 & 99.30 & 99.23 & 95.08 & 85.63 & 91.50 & 6.22 & 0.45 \\
\hline Day 56 & 81.42 & 75.63 & 75.86 & 80.46 & 75.85 & 4.55 & 0.82 \\
\hline Day 112 & $85.42^{\mathrm{b}}$ & $82.65^{b}$ & $79.39^{b}$ & $87.80^{\mathrm{a}, \mathrm{b}}$ & $95.23^{\mathrm{a}}$ & 3.35 & 0.02 \\
\hline Linear & 0.02 & 0.01 & 0.01 & 0.80 & 0.53 & & \\
\hline Quadratic & 0.03 & 0.01 & 0.03 & 0.26 & 0.01 & & \\
\hline \multicolumn{8}{|l|}{ NEFA, mM } \\
\hline Day 0 & 0.20 & 0.17 & 0.24 & 0.25 & 0.26 & 0.04 & 0.43 \\
\hline Day 56 & 0.11 & 0.18 & 0.15 & 0.13 & 0.14 & 0.02 & 0.10 \\
\hline Day 112 & $0.13^{\mathrm{b}}$ & $0.20^{\mathrm{a}}$ & $0.14^{\mathrm{b}}$ & $0.15^{\mathrm{b}}$ & $0.15^{b}$ & 0.02 & 0.03 \\
\hline Linear & 0.04 & 0.29 & 0.01 & 0.01 & 0.01 & & \\
\hline Quadratic & 0.06 & 0.85 & 0.16 & 0.02 & 0.03 & & \\
\hline
\end{tabular}

\footnotetext{
${ }^{\mathrm{a}, \mathrm{b}}$ Least square means within a row with different superscripts differ $(P<0.05)$.
}

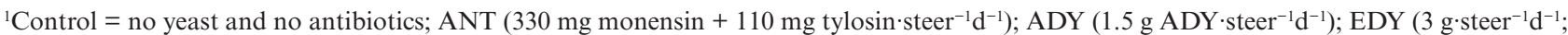
EDY consisted of $1.5 \mathrm{~g}$ ADY and $1.5 \mathrm{~g}$ capsule material); and MDY $\left(1.5 \mathrm{~g} \mathrm{ADY}+3.0 \mathrm{~g}\right.$ EDY $\left.\cdot \mathrm{steer}^{-1} \mathrm{~d}^{-1}\right)$; Treatment $\times$ days on-feed was significant at $P<0.05$ for blood urea $\mathrm{N}$ and blood glucose concentrations and at $P<0.08$ for blood NEFA.

${ }^{2}$ Ten steers from each treatment group were randomly selected for blood and fecal sample collection (Tables 4, 5 and 6).

${ }^{3} \mathrm{BUN}=$ blood urea $\mathrm{N}$

and a total loss of viability after simulated gastrointestinal digestion. Several reports stated that encapsulation may increase viability of probiotic bacteria against harsh environmental conditions of the gastrointestinal tract of animals (Chavarri et al., 2010; Ghorbani-Choboghlo et al., 2015). Our previous study (Jiao et al., 2017) showed that encapsulation of ADY resulted in improved yeast survival under simulated gastrointestinal conditions compared with unprotected ADY, indicating that ADY may enter the intestine without significant loss of viability. These results indicate that the capsule material protected the ADY from digestion in the rumen and abomasum, but the ADY was released from the capsule material in the intestine when subjected to pancreatic juice and bile. Therefore, encapsulation technologies offer promise for maintaining the viability of yeast cells after passing through the rumen and abomasum, to be released in the intestine.

\section{Effect of Yeast Supplementation on Growth Performance and Carcass Traits}

Feed intake responses of beef cattle to live yeast (LY) supplementation have been variable; some studies reported increased DMI (Robinson, 2010; Habeeb, 2017), whereas, other studies stated a reduction of DMI (Rodrigues et al., 2013; Sartori et al., 2017). Furthermore, there appears to be more studies that report no impact of LY supplementation on DMI than studies that report positive or negative effects (Beauchemin, 2012). These discrepancies among studies may be due to differences in yeast strains used (Newbold et al., 1995), the amount of yeast fed, type of animals, or the age of animals. In the current study, the lack of differences in overall DMI between control and yeast supplementation (ADY, EDY, and MDY) is in accordance with our previous study using beef heifers supplemented with protected or nonprotected ADY (Jiao et al., 2017). Vyas et al. (2014) also observed no difference in DMI by beef heifers fed ADY versus control diets. It is well established that DMI can be affected by ruminal digestibility and rate of passage of feeds out of the rumen. Jiao et al. (2017) reported that the ruminal fermentation characteristics and ruminal digestibility was not affected by supplementing ADY, EDY, or MDY; thus, the lack of yeast impact on DMI in the current study was as expected. Ruminal VFA concentrations exert some 
Table 5. Plasma acute phase protein concentration in finishing steers fed a diet supplemented with antibiotics (ANT), active dried yeast (ADY), encapsulated ADY (EDY), or mixture of ADY and EDY (MDY)

\begin{tabular}{|c|c|c|c|c|c|c|c|}
\hline \multirow[b]{2}{*}{ Item $^{1}$} & \multicolumn{5}{|c|}{ Treatments $^{2}$} & \multirow[b]{2}{*}{ SEM } & \multirow[b]{2}{*}{$P<$} \\
\hline & Control & ANT & ADY & EDY & MDY & & \\
\hline${\text { Animal } \#^{3}}$ & 10 & 10 & 10 & 10 & 10 & & \\
\hline \multicolumn{8}{|l|}{$\mathrm{Hp}, \mu \mathrm{g} / \mathrm{mL}$} \\
\hline Day 0 & 338 & 304 & 304 & 403 & 381 & 44.3 & 0.42 \\
\hline Day 56 & 197 & 213 & 188 & 177 & 236 & 20.9 & 0.32 \\
\hline Day 112 & $202^{\mathrm{b}}$ & $164^{b}$ & $356^{\mathrm{a}}$ & $359^{\mathrm{a}}$ & $372^{\mathrm{a}}$ & 22.0 & 0.01 \\
\hline Linear & 0.01 & 0.01 & 0.23 & 0.25 & 0.81 & & \\
\hline Quadratic & 0.05 & 0.53 & 0.01 & 0.01 & 0.01 & & \\
\hline \multicolumn{8}{|l|}{$\mathrm{SAA}, \mu \mathrm{g} / \mathrm{mL}$} \\
\hline Day 0 & 5.82 & 4.53 & 3.97 & 4.43 & 5.98 & 0.69 & 0.18 \\
\hline Day 56 & 5.54 & 5.92 & 3.54 & 5.24 & 5.03 & 0.63 & 0.14 \\
\hline Day 112 & $6.66^{\mathrm{a}}$ & $4.36^{\mathrm{b}, \mathrm{c}}$ & $5.60^{\mathrm{a}, \mathrm{b}}$ & $4.06^{\mathrm{c}}$ & $4.03^{\mathrm{c}}$ & 0.47 & 0.01 \\
\hline Linear & 0.33 & 0.88 & 0.04 & 0.65 & 0.02 & & \\
\hline Quadratic & 0.35 & 0.04 & 0.09 & 0.15 & 0.97 & & \\
\hline \multicolumn{8}{|l|}{$\mathrm{LBP}, \mu \mathrm{g} / \mathrm{mL}$} \\
\hline Day 0 & 17.96 & 15.31 & 13.93 & 14.95 & 18.71 & 1.66 & 0.21 \\
\hline Day 56 & $17.13^{b}$ & $25.43^{\mathrm{b}}$ & $22.90^{\mathrm{b}}$ & $33.78^{\mathrm{a}}$ & $32.99^{a}$ & 2.79 & 0.01 \\
\hline Day 112 & 39.73 & 38.12 & 40.71 & 31.42 & 31.62 & 4.13 & 0.33 \\
\hline Linear & 0.01 & 0.01 & 0.01 & 0.01 & 0.01 & & \\
\hline Quadratic & 0.01 & 0.72 & 0.23 & 0.01 & 0.03 & & \\
\hline
\end{tabular}

a,b,c Least square means within a row with different superscripts differ $(P<0.05)$.

${ }^{1} \mathrm{Hp}=$ haptoglobin; SAA = serum amyloid A; LBP = lipopolysaccharide binding protein.

${ }^{2}$ Control = no yeast and no antibiotics; ANT $\left(330 \mathrm{mg}\right.$ monensin $+110 \mathrm{mg}$ tylosin $\left.\cdot \mathrm{steer}^{-1} \mathrm{~d}^{-1}\right)$; ADY $\left(1.5 \mathrm{~g}\right.$ ADY $\left.\cdot \mathrm{steer}^{-1} \mathrm{~d}^{-1}\right)$; EDY $\left(3 \mathrm{~g} \cdot \mathrm{steer}{ }^{-1} \mathrm{~d}^{-1}\right.$; EDY consisted of $1.5 \mathrm{~g}$ ADY and $1.5 \mathrm{~g}$ capsule material); and MDY $\left(1.5 \mathrm{~g}\right.$ ADY $+3.0 \mathrm{~g}$ EDY $\left.\cdot \mathrm{steer}^{-1} \mathrm{~d}^{-1}\right)$; Treatment $\times$ days on-feed was significant at $P<0.01$ for Hp, SAA and LBP.

${ }^{3}$ Ten steers from each treatment group were randomly selected for blood and fecal sample collection (Tables 4-6).

control of DMI with propionate evoking a greater decrease in feed intake than acetate and butyrate (Allen, 2000). Total VFA concentration and molar proportion of acetate and propionate did not differ between heifers fed control or ADY in the study of Jiao et al. (2017). However, the numerically greater DMI $(+3.8 \%, P<0.11)$ on day 1 to 28 of steers supplemented with MDY compared with control steers in the current study is of interest because it suggests that MDY supplementation might have partially alleviated the negative impact of stress or rumen acidosis at the start of the study, as discussed previously (Yang et al., 2010). It has been suggested that feeding LY to receiving cattle can minimize the negative effects of adaptation on feed intake by altering ruminal fermentation patterns and improving cattle health (Adams et al., 1981; Finck et al., 2014). Mohammed et al. (2017) also reported that ADY supplementation reduced subacute rumen acidosis in beef heifers by reducing the duration of $\mathrm{pH}<5.8$ (indicative of subacute ruminal acidosis) when compared with control heifers when the cattle were exposed to an acidosis challenge.

The overall ADG and feed efficiency were not affected by LY supplementation in the present study.
Similarly, Mir and Mir (1994) reported that supplementation of LY in steer diets did not improve feed efficiency. However, in the current study, the improved ADG of steers fed MDY during day 1 to 28 indicates that feeding LY promoted growth performance in the beginning of the finishing period when LY was delivered in both rumen (ADY) and intestine (EDY). The steers might have been more stressed during the first few weeks of the study even though they were adapted to the high-grain diet during the transition period (Broadway et al., 2015). Supplementation of LY in both rumen and intestine (i.e., MDY) to steers appeared to mitigate adverse effects of the stress leading to numerically greater DMI and possibly improved intestinal function, and consequently improved ADG. However, the impact of LY supplementation may be diminished with increasing days on-feed as reported by Beauchemin et al. (2003). Improved performance of steers early in the study due to MDY supplementation may have been due to delivery of LY to both the rumen and intestine rather than only one site, or it might have been due to the greater total dose of LY for MDY ( $3 \mathrm{~g}$ ADY) compared with ADY (1.5 g/d) or EDY (1.5 g/d) alone. However, 
Table 6. Fecal pH, IgA, and Escherichia coli counts in finishing steers fed a diet supplemented with antibiotics (ANT), active dried yeast (ADY), encapsulated ADY (EDY), or mixture of ADY and EDY (MDY)

\begin{tabular}{|c|c|c|c|c|c|c|c|}
\hline \multirow[b]{2}{*}{ Item } & \multicolumn{5}{|c|}{ Treatments $^{1}$} & \multirow[b]{2}{*}{ SEM } & \multirow[b]{2}{*}{$P<$} \\
\hline & Control & ANT & ADY & EDY & MDY & & \\
\hline Animal\#² & 10 & 10 & 10 & 10 & 10 & & \\
\hline \multicolumn{8}{|l|}{$\mathrm{pH}$} \\
\hline Day 0 & 6.24 & 6.17 & 6.00 & 6.17 & 6.31 & 0.16 & 0.74 \\
\hline Day 56 & 6.52 & 6.53 & 6.59 & 6.45 & 6.52 & 0.11 & 0.81 \\
\hline Day 112 & 6.42 & 6.76 & 6.73 & 6.76 & 6.47 & 0.15 & 0.32 \\
\hline Linear & 0.29 & 0.01 & 0.01 & 0.01 & 0.18 & & \\
\hline Quadratic & 0.18 & 0.24 & 0.12 & 0.97 & 0.47 & & \\
\hline \multicolumn{8}{|l|}{$\operatorname{IgA}, \mu \mathrm{g} / \mathrm{g}$} \\
\hline Day 0 & $0.80^{\mathrm{b}}$ & $1.66^{\mathrm{a}}$ & $0.43^{\mathrm{b}}$ & $0.45^{\mathrm{b}}$ & $0.57^{\mathrm{b}}$ & 0.280 & 0.02 \\
\hline Day 56 & 0.24 & 0.22 & 0.26 & 0.28 & 0.44 & 0.084 & 0.33 \\
\hline Day 112 & 0.17 & 0.16 & 0.17 & 0.14 & 0.18 & 0.072 & 0.99 \\
\hline Linear & 0.01 & 0.01 & 0.01 & 0.01 & 0.01 & & \\
\hline Quadratic & 0.23 & 0.01 & 0.84 & 0.95 & 0.73 & & \\
\hline \multicolumn{8}{|l|}{ E. coli,$\times 10^{7}$} \\
\hline Day 0 & 17.34 & 14.75 & 6.35 & 8.24 & 11.56 & 2.101 & 0.07 \\
\hline Day 56 & 5.80 & 7.92 & 4.04 & 7.21 & 5.83 & 1.806 & 0.07 \\
\hline Day $112^{3}$ & 8.47 & 10.08 & 3.99 & 3.27 & 2.47 & 2.185 & 0.06 \\
\hline Linear & 0.01 & 0.01 & 0.39 & 0.01 & 0.01 & & \\
\hline Quadratic & 0.19 & 0.63 & 0.84 & 0.57 & 0.21 & & \\
\hline
\end{tabular}

\footnotetext{
${ }^{\mathrm{a}, \mathrm{b}}$ Least square means within a row with different superscripts differ $(P<0.05)$.
}

${ }^{1}$ Control $=$ no yeast and no antibiotics; ANT (330 mg monensin $+110 \mathrm{mg}$ tylosin $\left.\cdot \mathrm{steer}^{-1} \mathrm{~d}^{-1}\right)$; ADY (1.5 g ADY $\cdot$ steer $\left.{ }^{-1} \mathrm{~d}^{-1}\right)$; EDY $\left(3 \mathrm{~g} \cdot \mathrm{Eteer}^{-1} \mathrm{~d}^{-1}\right.$; EDY consisted of $1.5 \mathrm{~g}$ ADY and $1.5 \mathrm{~g}$ capsule material $)$; and MDY $\left(1.5 \mathrm{~g}\right.$ ADY $+3.0 \mathrm{~g}$ EDY $\cdot$ steer $\left.^{-1} \mathrm{~d}^{-1}\right)$; Treatment $\times$ days on-feed was significant at $P<0.01$ for $\operatorname{IgA}$.

${ }^{2}$ Ten steers from each treatment group were randomly selected for blood and fecal sample collection (Tables 4-6).

${ }^{3}$ ANT differed $(P<0.05)$ from ADY, EDY, and MDY.

the subsequently reduced ADG and G:F of steers fed EDY and MDY compared with control from day 29 to 56 suggests that the early benefits of feeding LY diminished with time on feed. Nevertheless, the reduced ADG of steers fed EDY or MDY from day 29 to 56 was compensated from day 57 to 84 , indicating fluctuation of growth performance throughout the finishing period. There are limited studies evaluating the effect of feeding LY on beef cattle growth performance in comparison with the considerable research that has been conducted with lactating dairy cows (Sartori et al., 2017). Lascano and Heinrichs (2007) concluded in a review that although results were highly variable, most studies reported limited influence of LY on DMI and ADG.

Feeding monensin to ruminants is known to reduce feed intake and improve feed efficiency (Tedeschi et al., 2003). In contrast, in the current study, overall DMI and G:F of steers supplemented with ANT did not differ from control steers. Comparisons of LY with monensin within the same study for effects on beef cattle growth performance are scarce. Erasmus et al. (2009) conducted a meta-analysis on the effect of LY addition fed with and without monensin to feedlot cattle fed high-grain diets. The ADG and G:F of cattle supplemented with either LY $(1.54 \mathrm{~kg} / \mathrm{d}$ and 0.156$)$ or monensin $(1.54 \mathrm{~kg} / \mathrm{d}$ and 0.158$)$ were not different. The absence of differences in ADG and G:F between steers fed LY and ANT in the present study appears to be consistent with our previous findings in beef heifers receiving the same dietary treatments (Jiao et al., 2017) as in the present study. In that study, ruminal total VFA concentration was not different among treatments, but ratio of acetate to propionate was less for ANT than yeast supplementation. Those results indicate that ANT may promote propiogenesis, which is energetically more favorable for growth and improved feed efficiency, whereas LY may promote acetogenesis through enhanced fiber digestion. In the previous study of Jiao et al. (2017) digestibility of OM in the total digestive tract was greater with yeast (ADY, EDY, and MDY) than ANT. Results suggest similar effects of either LY or monensin on growth performance of feedlot cattle although mechanisms differ.

The lack of treatment effects on growth performance likely account for the similar carcass characteristics among treatments. Very few studies have examined the effects of feeding LY on carcass traits. 
Liver abscesses are often associated with undesirable carcass traits (Brown and Lawrence, 2010; Rezac et al., 2014). Brown and Lawrence (2010) evaluated the association between liver abnormalities and carcass characteristics for 76,191 animals and found that mildly and severely abscessed livers were associated with reduced HCW, LM area, and 12th-rib subcutaneous fat. In the present study, proportion of severely abscessed livers was reduced by supplementing the diet with ruminally available ADY, although the proportion of total abscessed livers was not different among treatments. The lack of effect of ADY on HCW, LM area, 12th-rib subcutaneous fat, and marbling score in the present study suggests that the previously reported associated between liver abnormalities and carcass traits by Brown and Lawrence (2010) may have been mediated by reduced DMI or ADG, which was not observed in our study. The reduction in severely abscessed livers with ruminally available ADY suggests that ADY may have alleviated rumen acidosis. Rapid starch degradation in the rumen of steers fed high-grain diet can lower ruminal $\mathrm{pH}$ and cause digestive disturbances such as acidosis and rumenitis, increasing the incidence of liver abscesses (McAllister et al., 1990). Supplementing ADY may prevent risk of ruminal acidosis by reducing lactate production. Meanwhile, the lack of effect of EDY on the incidence of total and severely abscessed livers indicates that encapsulated ADY bypassed the rumen. The lack of effect of ANT on carcass characteristics observed in the present study is consistent with previous studies that showed feeding monensin had no significant effect on carcass characteristics (Goodrich et al., 1984; Swyers et al., 2014). Antibiotics, particularly tylosin, are commonly used to control liver abscesses in feedlot cattle by minimizing occurrence of acidosis and subsequent rumenitis (Amachawadi and Nagaraja, 2016). However, in the present study, supplementation of tylosin had no effect on liver abscesses, which was not expected and difficult to explain.

\section{Effect of Yeast Supplementation on Blood Metabolites and Immune Status}

Ruminal $\mathrm{NH}_{3}-\mathrm{N}$ concentration is a crude indicator of efficiency of dietary $\mathrm{N}$ conversion into microbial N (Firkins et al., 2007), while BUN concentration is useful as an indicator of protein status within a group of animals (Kohn et al., 2005). Studies reporting effects of LY on microbial N metabolism in the rumen are few and inconsistent (Chaucheyras-Durand et al., 2008). Our previous study (Jiao et al., 2017) using rumen cannulated heifers receiving the same treatments as in the present study showed adding rumen protected ADY (i.e., EDY and MDY) increased protein digestibility in the total digestive tract without changing ruminal $\mathrm{NH}_{3}-\mathrm{N}$ concentration and ruminal degradability of protein. Thus, the trend of greater BUN with EDY and MDY versus control in the current study suggests increased intestinal absorption of amino acids. In addition, the trend of greater BUN with ANT than control was possibly because monensin inhibited ruminal protein degradation, and thus feed protein digestion in the intestine increased (Tedeschi et al., 2003). These results suggest that feeding ruminally protected LY or monensin may potentially improve protein efficiency although the mode of action is different between LY and monensin.

Blood glucose and NEFA are important indicators of energy status. Because the energy requirement of the steers was met in the current study (NASEM, 2016), differences in blood glucose and NEFA concentrations were not expected. Nevertheless, greater blood glucose concentration in the steers supplemented with MDY on day 112 may be attributed to greater intestinal digestibility of OM, as observed previously in heifers fed MDY (Jiao et al., 2017). More net glucose can be transferred from the small intestine to the liver if more starch is digested in the small intestine. Similar blood glucose concentration among the other treatments is consistent with several studies carried out with lambs fed diets containing LY (Antunovic et al., 2005; Ding et al., 2008). Similar blood NEFA concentrations for steers fed yeast and control was expected, but the greater serum NEFA concentration in steers supplemented with ANT may have been caused by lower DMI due to monensin addition. Increased serum NEFA was also observed in a previous study in which steers fed high-grain diets were supplemented with monensin (Yang et al., 2010), although DMI was not different between monensin and control steers in that study.

The release of acute phase proteins is commonly attributed to activation of the innate immune response to inflammation, tissue injury, and infection (Murata et al., 2004; Gruys et al., 2005). It is known that endotoxin stimulates release of proinflammatory cytokines by liver macrophages which in turn activates hepatocytic receptors and initiates synthesis of acute phase proteins (Gruys et al., 2005). The SAA and LBP directly participate in detoxification and removal of endotoxin during the acute phase response. The SAA can bind and neutralize 
endotoxin and carry it to the liver to be excreted in bile, and intestinal epithelial cells can release SAA upon stimulation by the proinflammatory mediators (Vreugdenhil et al., 1999). The Hp is able to bind free hemoglobin, which is toxic and proinflammatory, in the plasma and reduce the oxidative damage associated with hemolysis (Murata et al., 2004). The LBP also participates in the detoxification and removal of endotoxin during an acute phase response (Schroedl et al., 2001). In the current study, the lowered plasma SAA concentrations on day 112 in steers supplemented with EDY and MDY suggests that adding protected ADY in high-grain diets may have reduced translocation of endotoxin through the hindgut into the bloodstream. Endotoxin can be released in both the rumen and hindgut (Li et al., 2016), but the site of translocation of endotoxin into blood (ruminal wall or hindgut epithelium) is not certain. The greater $\mathrm{Hp}$ of steers supplemented with EDY and MDY than that of control on day 112 was possibly caused by more free hemoglobin in the blood of steers supplemented with EDY and MDY. This effect is supported by 2.6 to $5.9 \%$ fewer red blood cells (Supplementary Table 1) in steers supplemented with EDY and MDY compared with control. Whether supplementing EDY and MDY to cattle fed high-grain diet can lead to hemolysis is not clear.

\section{Effect of Yeast Supplementation on Fecal Microflora and Immune Status}

The linear increase in fecal $\mathrm{pH}$ with increasing days on-feed indicates a reduction in carbohydrate fermentation in the hindgut over time. The differences in fecal IgA and E. coli counts among treatments on day 0 is consistent with the differences in blood lymphocyte and monocyte cells among treatments on day 0 (Supplementary Table 1), indicating that the animals were under different immune status at the start of the study. This initial difference led to the treatment $\times$ days on feed interaction, because there was a substantial decrease in fecal IgA concentration for all treatments as days on-feed increased. The IgA secreted by the gut plays a crucial role in the mucosal defense and fecal IgA concentration can be used as an indicator of mucosal immunity (Suzuki et al., 2004). The decreased fecal IgA concentration with prolonged days on-feed suggests a reduction in the need for an immune response.

Fecal E. coli counts also tended to differ among treatments at the start of the study, with lower fecal E. coli counts for steers supplemented with LY (ADY, EDY, and MDY) than control. These differences in fecal E. coli counts remained until day 112.
It suggests beneficial effects of LY on the intestinal ecosystem. A reduction of fecal $E$. coli was also observed when dairy goats were offered $0.2 \mathrm{~g} / \mathrm{d}$ of LY (Stella et al., 2007).

In conclusion, supplementation of a highgrain diet with ADY, either in encapsulated or nonencapsulated forms, as well as with ANT had overall no effects on DMI, final BW, ADG, feed efficiency, and most carcass characteristics when compared with control steers. Severely abscessed livers were reduced by supplementing the diet with ADY and MDY, indicating that ruminally available ADY may have alleviated rumen acidosis. The greater blood glucose concentrations with MDY suggest that more net glucose may have been transferred from the small intestine to the liver, although this potential improvement in energy efficiency did not enhance animal performance. The tendency for reduced fecal total $E$. coli counts with all three yeast treatments suggests possible antipathogenic activity of ADY in the lower gut. Supplementation with monensin and tylosin reduced DMI compared with LY treatments, but did not enhance feed efficiency. The study suggests that feeding ADY to feedlot cattle may exert potential beneficial health and food safety effects that reduce liver abscess and possibly pathogen excretion. Thus, yeast can be used as an alternative to in-feed antibiotics in natural beef cattle production systems.

\section{SUPPLEMENTARY DATA}

Supplementary data are available at Journal of Animal Science online.

Conflict of interest statement. None declared.

\section{LITERATURE CITED}

Abd El-Tawab, M. M., I. M. Youssef, H. A. Bakr, G. C. Fthenakis, and N. D. Giadinis. 2016. Role of probiotics in nutrition and health of small ruminants. Pol. J. Vet. Sci. 19:893-906. doi:10.1515/pjvs-2016-0114

Adams, D. C., M. L. Galyean, H. E. Kiesling, J. D. Wallace, and M. D. Finkner. 1981. Influence of viable yeast culture, sodium bicarbonate and monensin on liquid dilution rate, rumen fermentation and feedlot performance of growing steers and digestibiliy in lambs. J. Anim. Sci. 53:780-788. doi:10.2527/jas 1981.533780x

Allen, M. S. 2000. Effects of diet on short-term regulation of feed intake by lactating dairy cattle. J. Dairy Sci. 83:15981624. doi:10.3168/jds.S0022-0302(00)75030-2

Amachawadi, R. G., and T. G. Nagaraja. 2016. Liver abscesses in cattle: a review of incidence in holsteins and of bacteriology and vaccine approaches to control in feedlot cattle. J. Anim. Sci. 94:1620-1632. doi:10.2527/ jas.2015-0261 
Antunovic, Z., M. Speranda, B. Liker, V. Seric, D. Sencic, M. Domacinovic, and T. Speranda. 2005. Influence of feeding the probiotic Pioneer PDFM ${ }^{\circledR}$ to growing lambs on performances and blood composition. Acta. Vet.Beograd. 55:287-300. doi:10.2298/AVB0504287A

Ashima, V., S. Poonam, and M. Anshu. 2016. Probiotic yeasts in livestock sector. Anim. Feed Sci. Tech. 219:31-47. doi:10.1016/j.anifeedsci.2016.05.019

Beauchemin, K. A. 2012. Use of yeast in ruminant diets. In: Proc. the 33rd Western Nutr. Conf. September 19-20, Winnipeg, Manitoba. p. 122.

Beauchemin, K. A., W. Z. Yang, D. P. Morgavi, G. R. Ghorbani, W. Kautz, and J. A. Leedle. 2003. Effects of bacterial direct-fed microbials and yeast on site and extent of digestion, blood chemistry, and subclinical ruminal acidosis in feedlot cattle. J. Anim. Sci. 81:1628-1640. doi:10.2527/2003.8161628x

Broadway, P. R., J. A. Carroll, and N. C. Sanchez. 2015. Live yeast and yeast cell wall supplements enhance immune function and performance in food-producing livestock: a review $(\dagger),(\dagger)$. Microorganisms 3:417-427. doi:10.3390/ microorganisms3030417

Brown, T. R., and T. E. Lawrence. 2010. Association of liver abnormalities with carcass grading performance and value. J. Anim. Sci. 88:4037-4043. doi:10.2527/jas.2010-3219

Canadian Council on Animal Care. 2009. Guide to the care and use of farm animals in research teaching and testing. E. D. Olfert, B. M. Cross, and A. A. McWilliam, editors. Can. Counc. Anim. Care, Ottawa, Ontario, Canada.

Chaucheyras-Durand, F., N. D. Walker, and A. Bach. 2008. Effects of active dry yeasts on the rumen microbial ecosystem: past, present and future. Anim. Feed Sci. Technol. 145:5-26. doi:10.1016/j.anifeedsci.2007.04.019

Chávarri, M., I. Marañón, R. Ares, F. C. Ibáñez, F. Marzo, and M. d. e. 1. C. Villarán. 2010. Microencapsulation of a probiotic and prebiotic in alginate-chitosan capsules improves survival in simulated gastro-intestinal conditions. Int. J. Food Microbiol. 142:185-189. doi:10.1016/j. ijfoodmicro.2010.06.022

Denev, S. A., T. P. P. Radulova, N. Stancheva, G. Staykova, G. Beev, P. Todorova, and S. Tchobanova. 2007. Yeast cultures in ruminant nutrition. Bulg. J. Agric. Sci. 13:357-374.

Ding, J., Z. M. Zhou, L. P. Ren, and Q. X. Meng. 2008. Effect of monensin and live yeast supplementation on growth performance, nutrient digestibility, carcass characteristics and ruminal fermentation parameters in lambs fed steamflaked corn-based diets. Asian-Aust. J. Anim. Sci. 21:547554. doi:10.5713/ajas.2008.70353

Erasmus L. J., R. F. Coertze, M. N. Leviton, and E. Chevaux. 2009. A meta-analysis of the effect of monensin or live yeast or a combination there of on performance of beef cattle. J. Anim. Sci. 87 (E-Suppl. 2):281.

Finck, D. N., F. R. B. Ribeiro, N. C. Burdick, S. L. Parr, J. A. Carroll, T. R. Young, B. C. Bernhard, J. R. Corley, A. G. Estefan, R. J. Rathmann, et al. 2014. Yeast supplementation alters the performance and health status of receiving cattle. Prof. Anim. Sci. 30:333-341. doi:10.15232/ S1080-7446(15)30125-X

Firkins, J. L., Z. Yu, and M. Morrison. 2007. Ruminal nitrogen metabolism: perspectives for integration of microbiology and nutrition for dairy. J. Dairy Sci. 90(Suppl. 1):E1-16. doi:10.3168/jds.2006-518
Fratianni, F., F. Cardinale, I. Russo, C. Iuliano, P. Tremonte, R. Coppola, and F. Nazzaro. 2014. Ability of synbiotic encapsulated Saccharomyces cerevisiae boulardii to grow in berry juice and to survive under simulated gastrointestinal conditions. J. Microencapsul. 31:299-305. doi:10.310 9/02652048.2013.871361

Ghorbani-Choboghlo, H., T. Zahraei-Salehi, J. Ashrafi-Helan, R. Yahyaraeyat, H. Pourjafar, D. Nikaein, A. Balal, and A. R. Khosravi. 2015. Microencapsulation of Saccharomyces cerevisiae and its evaluation to protect in simulated gastric conditions. Iran. J. Microbiol. 7:338-342.

Goodrich, R. D., J. E. Garrett, D. R. Gast, M. A. Kirick, D. A. Larson, and J. C. Meiske. 1984. Influence of monensin on the performance of cattle. J. Anim. Sci. 58:1484-1498.

Gruys, E., M. J. Toussaint, T. A. Niewold, and S. J. Koopmans. 2005. Acute phase reaction and acute phase proteins. J. Zhejiang Univ. Sci. B. 6:1045-1056. doi:10.1631/jzus.2005. B1045

Habeeb, A. A. M. 2017. Importance of yeast in ruminants feeding on production and reproduction. Ecol. Evol. Biol. 2:49-58. doi:10.11648/j.eeb.20170204.11

Jiao, P. X., L. Y. Wei, N. D. Walker, F. Z. Liu, L. Y. Chen, K. A. Beauchemin, and W. Z. Yang. 2017. Comparison of non-encapsulated and encapsulated active dried yeast on ruminal $\mathrm{pH}$ and fermentation, and site and extent of feed digestion in beef heifers fed high-grain diets. Anim. Feed Sci. Technol. 288:13-22. doi:10.1016/j. anifeedsci.2017.04.001

Kohn, R. A., M. M. Dinneen, and E. Russek-Cohen. 2005. Using blood urea nitrogen to predict nitrogen excretion and efficiency of nitrogen utilization in cattle, sheep, goats, horses, pigs, and rats. J. Anim. Sci. 83:879-889. doi: $10.2527 / 2005.834879 \mathrm{x}$

Lascano, G. J., and A. J. Heinrichs. 2007. Yeast culture (Saccharomyces cerevisiae) supplementation in growing animals in the dairy industry. CAB Reviews: Perspectives in Agriculture, Veterinary Science, Nutrition and Natural Resources. 2:049. doi:10.1079/PAVSNNR20072049

Liong, M. T. 2007. Probiotics: a critical review of their potential role as antihypertensives, immune modulators, hypocholesterolemics, and perimenopausal treatments. Nutr. Rev. 65:316-328.

Li, S., I. Yoon, M. Scott, E. Khafipour, and J. Plaizier, 2016. Impact of Saccharomyces cerevisiae fermentation product and subacute ruminal acidosis on production, inflammation, and fermentation in the rumen and hindgut of dairy cows. Anim. Feed Sci. Technol. 211:50-60. doi:10.1016/ j.anifeedsci.2015.10.010

McAllister, T. A., K. A. Beauchemin, A. Y. Alazzeh, J. Baah, R. M. Teather, and K. Stanford. 2011. Review: the use of direct fed microbials to mitigate pathogens and enhance production in cattle. Can. J. Anim. Sci. 91:193-211. doi:10.4141/cjas10047

McAllister, T. A., K. J. Cheng, L. M. Rode, and J. G. BuchananSmith. 1990. Use of formaldehyde to regulate digestion of barley starch. Can. J. Anim. Sci. 70:581-589. doi:10.4141/ cjas90-070

Mir, Z., and P. S. Mir. 1994. Effect of the addition of live yeast (Saccharomyces cerevisiae) on growth and carcass quality of steers fed high-forage or high-grain diets and on feed digestibility and in situ degradability. J. Anim. Sci. 72:537-545.

Mohammed, R., D. Vyas, W. Z. Yang, and K. A. Beauchemin. 2017. Changes in the relative population size of selected 
ruminal bacteria following an induced episode of acidosis in beef heifers receiving viable and non-viable active dried yeast. J. Appl. Microbiol. 122:1483-1496. doi:10.1111/jam.13451

Murata, H., N. Shimada, and M. Yoshioka. 2004. Current research on acute phase proteins in veterinary diagnosis: an overview. Vet. J. 168:28-40. doi:10.1016/ S1090-0233(03)00119-9

National Academies of Sciences, Engineering, and Medicine (NASEM). 2016. Nutrient Requirements of Beef Cattle. 8th rev. ed. Natl. Acad. Press, Washington, DC.

Newbold, C. J., R. J. Wallace, X. B. Chen, and F. M. McIntosh. 1995. Different strains of saccharomyces cerevisiae differ in their effects on ruminal bacterial numbers in vitro and in sheep. J. Anim. Sci. 73:1811-1818.

NRC. 2000. Nutrient requirements of beef cattle. 7th rev. ed., Update 2000. Natl. Acad. Sci., Washington, DC.

Petran, R. L., L. E. Grieme, and S. Foong-Cunningham. 2001. Culture methods for enumeration of microorganisms. In: F. P. Downes and K. Ito, editors, Compendium of methods for the microbiological examination of foods, 4 th ed. American public health association, Washington, DC. doi:10.2105/MBEF.0222.011

Rezac, D. J., D. U. Thomson, S. J. Bartle, J. B. Osterstock, F. L. Prouty, and C. D. Reinhardt. 2014. Prevalence, severity, and relationships of lung lesions, liver abnormalities, and rumen health scores measured at slaughter in beef cattle. J. Anim. Sci. 92:2595-2602. doi:10.2527/jas.2013-7222

Robinson, P. H. 2010. Yeast products for growing and lactating ruminants: a literature summary of impacts on rumen fermentation and performance. Cooperative Extension Specialist Department of Animal Science, University of California, Davis, CA.

Rodrigues, E., M. D. B. Arrigoni, C. R. M. Andrade, C. L. Martins, D. D. Millen, F. S. Parra, and C. Andrighetto. 2013. Performance, carcass characteristics and gain cost of feedlot cattle fed a high level of concentrate and different feed additives. Rev. Bras. Zootec. 42:61-69. doi:10.1590/ S1516-35982013000100009

Sartori, E. D., E. A. C. Maria, Z. Daniele, R. P. Enio, P. V. Joao, and O. J. B. Julio. 2017. The effect of live yeast supplementation on beef cattle performance: a systematic review and meta-analysis. J. Agr. Sci. 9:21-37. doi:10.5539/jas.v9n4p21

Schroedl, W., B. Fuerll, P. Reinhold, M. Krueger, and C. Schuett. 2001. A novel acute phase marker in cattle: lipopolysaccharide binding protein (LBP). J. Endotoxin Res. 7:49-52.

Shen, Y., P. Jiao, H. Wang, L. Chen, N. D. Walker, and W. Yang. 2017. Validation of micro-encapsulation method to protect probiotics and feed enzyme from rumen degradation. J. Anim. Sci. 95(Suppl. 4): P317 (Abstract).
Stella, A. V., R. Paratte, L. Valnegri, G. Cigalino, G. Soncini, E. Chevaux, V. Dell'Otro, and G. Savoini. 2007. Effect of administration of live Saccharomyces cerevisiae on milk production, milk composition, blood metabolites and faecal flora in early lactating dairy goats. Small Rumin. Res. 67:7-13. doi:10.1016/j.smallrumres.2005.08.024

Sullivan, M. L., and B. J. Bradford. 2011. Viable cell yield from active dry yeast products and effects of storage temperature and diluent on yeast cell viability. J. Dairy Sci. 94:526-531. doi:10.3168/jds.2010-3553

Suzuki, K., B. Meek, Y. Doi, M. Muramatsu, T. Chiba, T. Honjo, and S. Fagarasan. 2004. Aberrant expansion of segmented filamentous bacteria in iga-deficient gut. Proc. Natl. Acad. Sci. USA. 101:1981-1986. doi:10.1073/ pnas.0307317101

Swyers, K. L., J. J. Wagner, K. L. Dorton, and S. L. Archibeque. 2014. Evaluation of saccharomyces cerevisiae fermentation product as an alternative to monensin on growth performance, cost of gain, and carcass characteristics of heavy-weight yearling beef steers. J. Anim. Sci. 92:25382545. doi:10.2527/jas.2013-7559

Tedeschi, L. O., D. G. Fox, and T. P. Tylutki. 2003. Potential environmental benefits of ionophores in ruminant diets. J. Environ. Qual. 32:1591-1602.

USDA. 1989. Official united states standards for grades of carcass beef. Agric. Mark. Serv., USDA, Washington, DC.

Vreugdenhil, A. C., M. A. Dentener, A. M. Snoek, J. W. Greve, and W. A. Buurman. 1999. Lipopolysaccharide binding protein and serum amyloid A secretion by human intestinal epithelial cells during the acute phase response. J. Immunol. 163:2792-2798.

Vyas, D., A. Uwizeye, R. Mohammed, W. Z. Yang, N. D. Walker, and K. A. Beauchemin. 2014. The effects of active dried and killed dried yeast on subacute ruminal acidosis, ruminal fermentation, and nutrient digestibility in beef heifers. J. Anim. Sci. 92:724-732. doi:10.2527/ jas.2013-7072

Wang, R., Z. Tian, and L. Chen. 2011. A novel process for microencapsulation of fish oil. Food Res. Int. 44:27352741. doi:10.1016/j.foodres.2011.06.013

WHO. 2006. Report of a Joint FAO/OIE/WHO expert consultation on antimicrobial use in aquaculture and antimicrobial resistance. Seoul Republicof Korea. 13-16 June 2006. World Health Organization. http://www.who.int/ iris/handle/10665/133869

Yang, W. Z., B. N. Ametaj, C. Benchaar, M. L. He, and K. A. Beauchemin. 2010. Cinnamaldehyde in feedlot cattle diets: intake, growth performance, carcass characteristics, and blood metabolites. J. Anim. Sci. 88:1082-1092. doi:10.2527/jas.2008-1608 